\title{
Comprehensive Comparison between Empty- nesters and Non-empty-nesters in Anhui, China: Subjective Well-being and Depression
}

Dan Su ( $\square$ sudanwu1986@163.com )

Anhui Medical University

Primary research

Keywords: Aging, Emotion, Psychology, Stress

Posted Date: May 28th, 2020

DOI: https://doi.org/10.21203/rs.3.rs-29125/v1

License: (1) (1) This work is licensed under a Creative Commons Attribution 4.0 International License.

Read Full License 


\section{Abstract}

BACKGROUND: China is one of the countries facing the most serious population aging. Empty-nesters accounted half of the total old adults in China, improving mental health status of old people is necessary. This cross-sectional study aimed to compare the subjective well-being and depression comprehensively between empty-nesters and non-empty-nesters in Anhui, China.

METHODS: 1452 participants were surveyed by using the demographic characteristics questionnaire, the subjective well-being (SWB) single-choice facial expression questionnaire and the 30-item Geriatric Depression Scale (GDS-30).

RESULTS: Education level and depression were risk factors for both groups $(P<0.05)$, but age, marital status, living mode, and religious belief were main risk factors for empty-nesters $(P<0.05)$. Monthly individual income and SWB were risk factors for both groups $(P<0.05)$, but living mode, religious belief and physical exercise were main risk factors for elderly empty-nesters, whereas economy situation was the main risk factor for non-empty-nesters $(P<0.05)$.

CONCLUTION: The influencing factors of two groups had similarities and differences. With the aging population of China, improving mental health status of old people was necessary. We should implement targeted interventions addressing mental health influencing factors of older adults.

\section{Background}

By 2014, The number of older adults aged 60 years and above reached 212 million in China, over 15percent of total Chinese population[1]; Predictive, the number would increase to 430 million by 2050[2], at that time, China will be the country facing the most serious population aging[3]. Accompanying with aging population, situation of Chinese abundant labor will change negatively because of increasing burden from elderly. Consequently, even economic promotion will go downhill. Additionally, young workforce is concentrating in big city along with accelerated urbanization process, which means more and more old people are becoming empty-nesters [4,5]. Empty-nester is a big and special group in China, as well as their mental health and medical care are primary health problems for the country.

Empty-nesters refer to older people live alone and their children have to left work. Empty-nesters accounted half of the total old adults in China[1]. Additionally, empty-nesters are more likely to conduct mental health problem called "empty-nest syndrome", including triggering negative emotions and psychological problems such as restlessness and sadness, possibly caused by lack of affection and spiritual comfort from their children[6]. Strong negative association between empty-nester and overall health has been reported[7], especially regarding psychological distress risk[8] and changes in self-rated health[9].

It's reported that living alone is associated with low subjective well-being (SWB) in elderly people, and older adults living with their direct relatives own positive SWB. SWB is a broad category of phenomena 
that includes domain satisfactions, global judgments of life satisfaction and people's emotional responses[10]. SWB has been used as a scientific observation index to measure people's happiness or satisfaction in a nation[11].

Compared to the general older people, empty-nesters have a higher risk for mental illness, such as anxiety[4] and loneliness [12]. With the gradually aging of the body, the individual's organizational structure and brain function become vestigial obviously, which promotes the "empty-nesters" to produce many psychological disorders. To the empty-nesters, loneliness is the biggest problem, which is the risk factor of depressive symptoms; there are potential associations between higher-level loneliness and more depressive symptoms [13]. For older people, depressive symptoms can appear spontaneously accompanying with loss of social support from work and less in time support from their children[14]. Similar findings have been reported by other researchers [15].

This cross-sectional study was designed to compare the subjective well-being and depression comprehensively between the empty-nesters and non-empty-nesters in Anhui, China; As well as to explore the different influencing factors of SWB and GDS in the two groups, with the intention of improving their mental health and quality of life.

\section{Methods}

\section{Study design and participants}

The designed cross-sectional survey was conducted in Hefei, capital city of Anhui Province, China. We used the stratified convenience cluster sampling method. The capital city Hefei, located in the central of Anhui, has nine districts (Yaohai, Luyang, Shushan, Baohe, Changfeng, Feixi, Feidong, Lujiang and Chaohu). Inclusion criteria: (1) aged 60 years or older; (2) had no cognitive disorder; and (3) being informed consent. Older people with cognitive disorder or serious diseases, such as psychiatric disorders, were excluded from the study.

All participants were informed of study procedure upon their recruitment. After obtaining written consent, participants were interviewed by trained study interviewers. The Ethics Committee of our University approved this study. Between March and December2019, 1480 individuals were contacted, and 1452 completed the questionnaire with the response rate98.1\%.

\section{Measurements}

Demographic characteristics were collected, including gender, age, child visit intervals, economy situation, marital status, education level, monthly individual income, living mode, chronic disease, religious belief and physical exercise.

The SWB single-choice facial expression questionnaire was used to assess the SWB of participants. This questionnaire was developed to test the current happiness of the subjects[16], the facial expressions were divided into 7 levels from very sad to very happy, which are marked as 1-7 points respectively. These 
subjects are asked to choose the most suitable expression for their feelings, and the higher of the score, the more satisfied with life.

The Geriatric Depression Scale (GDS) was applied to assess the depression of participants, which consist of 30 items[17]. In the week prior to the survey, participants completed every item with 'yes' and 'no' based on their own feelings. A total score $<11$ was considered non-depressed, 11 to 20 was classified as mild depression, 21 to 30 was moderate to severe depression. The Cronbach's Alpha coefficient for the GDS was $0.873[18]$.

\section{Data analysis}

All information was analyzed by usingSPSS23.0.Statistical description was carried out for sociodemographic data. Chi-squared test was conducted to compare the socio-demographic factors between the empty-nesters and non-empty-nesters. Independent t-test was used to compare SWB and GDS scores between the two groups. Pearson's correlation was conducted to assess the correlation between the SWB, depression and socio-demographic. Multivariate linear regression with enter analysis was used to study the significant factors predictive of SWB and depression. All tests were two-sided and $P<0.05$ was considered statistically significant.

\section{Result}

\section{Descriptive statistics}

The socio-demographic characteristics were presented in Table 1. Total of 1452 respondents, 812 (55.9\%) empty-nesters and 640 (44.1\%) non-empty-nesters, were enrolled in the final analysis. Chi-squared-test revealed significant differences between the two groups in education level, marital status, chronic disease, religious belief and physical exercise ( $P<0.05$; Table 1). No significant difference between two groups in age, gender, economy situation, monthly individual income and living mode ( $P>0.05)$.

Insert Table1 here

\section{SWB and GDS scores in the study groups}

Of all 1452 participants, the SWB score was range0-7 (3.96 \pm 1.47$)$, the GDS score was range0-88 (20.27 \pm 10.04$)$; GDS score $<11$ was 359 (24.7\%),GDS score $\geq 11$ was 1093 (75.3\%).For the empty-nesters

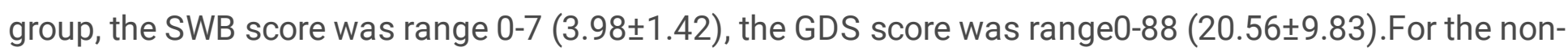

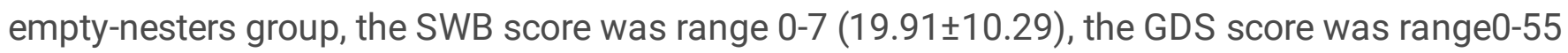
$(30.89 \pm 18.80)$. The independent sample $t$-test showed that there was no significant difference in SWB and depression between the two groups ( $P>0.05)$.

\section{Association between SWB and depression, socio-demographic variables in participants}


The correlations among SWB, depression and socio-demographic were shown in Table 2. SWB was negatively relevant with GDS scores and economy situation both in the empty-nesters and non-emptynesters $(P<0.01)$. In empty-nesters group, SWB was positively relevant to age $(P<0.05)$, and negatively relevant to education level $(P<0.01)$. For the non-empty-nesters group, SWB was positively relevant to monthly individual income $(P<0.01)$

Insert Table2 here

\section{Factors comparison of SWB between the empty-nesters and non-empty-nesters}

Table3 showed results of the multiple linear regressions for SWB with the socio-demographic variables and depression. The finding revealed that education level and depression were risk factors in both groups. But age, marital status, living mode, and religious belief were main risk factors in the emptynesters. In the regression model, $46.9 \%$ of the variance in SWB was explained for empty-nesters, and $61.1 \%$ of the variance for non-empty-nesters.

\section{Insert Table3 here}

\section{Factors comparison of depression between the empty-nesters and non-empty-nesters}

Table4 showed results of the multiple linear regressions for depression with socio-demographic variables and SWB. The finding revealed that monthly individual income and SWB were risk factors for both groups. But living mode, religious belief and physical exercise were main risk factors in the empty-nesters group, whereas economy situation was the main risk factor in the non-empty-nesters group. In the regression model, $46.9 \%$ of the variance in GDS was explained for empty-nesters, and $63.7 \%$ of the variance for non-empty-nesters.

\section{Insert Table4 here}

\section{Discussion}

China's elderly people have made up a large proportion of the whole [19], and the study on mental health of older adults is necessary. As reported, empty-nest families account for almost $25 \%$ of elderly household in China, and would increase to $90 \%$ by 2030[20].As a special group, mental health and its related factors are very important problems for the empty-nesters. So, at present, the empty-nesters' mental health problem is one of the primary problems affecting China's social development [3].

The current findings showed that the empty-nesters were mostly lower education level, married, having 1 type chronic disease, non-religious and exercising regularly compared with non-empty-nesters.

Differences of distribution between the two groups existed in education level, possibly because most of 
empty-nesters lived in rural places where lower level of education had. In China, if the old people was single(divorced or widowed), children or other immediate relatives would live with them and take care of them. Also, most of the empty-nesters had non-religious, which was consistent with previous study[21].Empty-nesters often had 1 type chronic disease, which maybe caused by upturn living standards and less health knowledge. Differences of distribution between two groups existed in physical exercise possibly because the empty-nesters had more free time than non-empty-nesters, Chinese nonempty-nesters often need to take care of their grandchildren.

Three fourths of our participants had depressive symptoms, which was similar to a previous study in Chizhou [13]. That means we should pay more attention to old people' mental health in Anhui, China. However, there were some findings inconsistent with previous studies [13,22]; our study revealed that no significant differences existed in SWB and depression between the two groups. This was an unexpected and interesting result. What is the reason? During the investigation, we found that most participants of empty-nesters lived nearby their children, though they did not live in the same house, they could meet each other easily. In busy season, they often worked alongside children in the fields, in leisure time, they often got together to take part in activities such as going to market and playing poker. Our result showed that no significant difference between the two groups in monthly individual income, which may narrow the gap between the empty-nesters and non-empty-nesters.

This survey found that SWB was negatively related to depression in both groups, which was in line with the previous study[23].Due to the lack of mental health care from the children, the elderly people were more likely to have negative emotions such as depression, which will affect their SWB and thus their life quality. Another interesting finding from this survey was that SWB negatively related to economy situation, if elderly were rich, they would have lower SWB. Psychological needs would be pursued while physiological needs had been satisfied, that maybe the most possible reason of this result. On the other hand, for the non-empty-nesters group, if their family had more monthly individual income, they would have higher SWB. Those indicate that children's prosperous life is more important to elderly people than themselves. For the empty-nesters group, the older they were, the higher SWB they had, that maybe because the longer they lived, the more content they would be. We also found that the higher of education level, the lower of SWB in empty-nesters group. The most possible reason was educated elderly people would pursue higher psychological needs. These findings prompt us to focus on that personal wellness but a poor family, older and educated elderly people, tries to satisfy their psychological needs.

Besides some aforementioned differences, multivariate analyses still showed several disparity factors in SWB between the two groups, including age, marital status, living mode, and religious belief. Based on empty-nesters as a vulnerable population, older, lower education level, married, living with spouse, religious and lower depression level might be promoting factors for SWB. Nevertheless, higher education level and lower depression level were possible promoting factors among non-empty-nesters. Multivariate analyses also showed several disparity factors in GDS between the two groups, including living mode, religious belief, physical exercise and economy situation. More monthly individual income, living with spouse, non-religious, frequent physical exercise, and higher SWB might be protective factors for GDS 
among empty-nesters. Nevertheless, worse economy situation, more monthly individual income and lower depression level were perhaps protective factors among non-empty-nesters. So, this study showed that we should formulate different effective measures for the two groups to increase their SWB and reduce the prevalence of depression depending on their related factors.

This study had several limitations. First, this study was cross-sectional, the results cannot explain causal relationships among the variables. Second, limited location and sample size of the study would reduce the generality of our result. Thus, these findings may not be representative of the elderly populations in other areas. Because of these limitations, the results of this study should be reviewed cautiously.

\section{Conclusions}

In summary, our study reported the SWB, depression and their related risk factors among the emptynesters and non-empty-nesters in Hefei, Anhui Province. For empty-nesters group, education level, depression, age, marital status, living mode, and religious belief were the influencing factors of SWB; monthly individual income, SWB, living mode, religious belief and physical exercise were the influencing factors of GDS. For non-empty-nesters group, education level and depression were the influencing factors of SWB; monthly individual income, SWB and economy situation were the influencing factors of GDS. These findings indicated that among the rapidly growing elderly population of China, improving mental health status is necessary. We should implement targeted interventions addressing mental health influencing factors of older adults.

\section{Declarations}

\section{Ethics approval and consent to participate}

This study received Institutional Review Board approval of Anhui Medical University $\mathbb{N}$ No:20180067区.

\section{Consent for publication}

Not applicable.

\section{Availability of data and material}

The raw data required to reproduce these findings cannot be shared at this time as the data also forms part of an ongoing study.

\section{Competing interests}

We declare that we do not have any commercial or associative interest that represents a conflict of interest in connection with the work submitted.

\section{Funding}


Natural Science Foundation of the Anhui Higher Education Institutions of China (Grant No. KJ2018A0176); Anhui Provincial General Teaching Research Project (Grant No. 2018jyxm0773).

\section{Authors' contributions}

Dan Su designed the study, collected the samples and wrote the manuscript.

\section{Acknowledgements}

This study was supported by a grant from Natural Science Foundation of the Anhui Higher Education Institutions of China (to Dan Su) (No. KJ2018A0176) and Anhui Provincial General Teaching Research Project (to Dan Su) (No. 2018jyxm0773). We would like to thank the participants in this study, who kindly agreed to provide the needed data.

\section{References}

1. Wang L, Shentu Q, Xu B et al. The prevalence of anxiety on the empty-nest elders in China. J Health Psychol 2018, DOI: 10.1177/1359105318776727: 1359105318776727

2. Du $P$, Yang H. China's population ageing and active ageing. China Journal of Social Work 2010; 3: 139-152

3. Guo YQ, Zhang CC, Huang $\mathrm{H}$ et al. Mental health and related influencing factors among the emptynest elderly and the non-empty-nest elderly in Taiyuan, China: a cross-sectional study. Public Health 2016; 141: 210-217

4. Lv XL, Jiang YH, Sun YH et al. Short form 36-Item Health Survey test result on the empty nest elderly in China: a meta-analysis. Arch Gerontol Geriatr 2013; 56: 291-297

5. Yuan R, Ngai SS. Social exclusion and neighborhood support: a case study of empty-nest elderly in urban Shanghai. J Gerontol Soc Work 2012; 55: 587-608

6. Wang J, Zhao X. Empty nest syndrome in China. Int J Soc Psychiatry 2012; 58: 110

7. Zhang $L$, Zeng Y, Fang Y. The effect of health status and living arrangements on long term care models among older Chinese: A cross-sectional study. PLoS One 2017; 12: e0182219

8. Amagasa S, Fukushima N, Kikuchi H et al. Types of social participation and psychological distress in Japanese older adults: A five-year cohort study. PLoS One 2017; 12: e0175392

9. Wang J, Chen T, Han B. Does co-residence with adult children associate with better psychological well-being among the oldest old in China? Aging Ment Health 2014; 18: 232-239

10. Diener E, Suh, E. , Lucas, R. E. , \& Smith, H. . Subjective well-being: three decades of progress. Social Science Electronic Publishing 1999; 125: 276-302

11. Lun MC, \& Bond, M. H. . Achieving subjective well-being around the world: the moderating influence of gender, age and national goals for socializing children. Journal of Happiness Studies 2016; 17: 587-608 
12. Wu ZQ, Sun L, Sun YH et al. Correlation between loneliness and social relationship among empty nest elderly in Anhui rural area, China. Aging Ment Health 2010; 14: 108-112

13. Cheng $P$, Jin $Y$, Sun $\mathrm{H}$ et al. Disparities in prevalence and risk indicators of loneliness between rural empty nest and non-empty nest older adults in Chizhou, China. Geriatr Gerontol Int 2015; 15: 356-364

14. Agosti MT, Andersson I, Ejlertsson $G$ et al. Shift work to balance everyday life - a salutogenic nursing perspective in home help service in Sweden. BMC Nurs 2015; 14: 2

15. Domenech-Abella J, Lara E, Rubio-Valera $M$ et al. Loneliness and depression in the elderly: the role of social network. Soc Psychiatry Psychiatr Epidemiol 2017; 52: 381-390

16. Andrews FM, Withey SB. Social Indicators of Well-Being; 1976

17. Yesavage JA, Brink TL, Rose TL et al. Development and validation of a geriatric depression screening scale: a preliminary report. J Psychiatr Res 1982; 17: 37-49

18. Wang XD. Mental health rating scale manual. Beijing: Chinese Mental Health Journal; 1999

19. Dai H, Jia G, Liu K. Health-related quality of life and related factors among elderly people in Jinzhou, China: a cross-sectional study. Public Health 2015; 129: 667-673

20. Wang G, Hu M, Xiao SY et al. Loneliness and depression among rural empty-nest elderly adults in Liuyang, China: a cross-sectional study. BMJ Open 2017; 7: e016091

21. Su D, Wu XN, Zhang YX et al. Depression and social support between China' rural and urban emptynest elderly. Arch Gerontol Geriatr 2012; 55: 564-569

22. Xu J, Sun Y, Wang Z. Prevalence and risk factors of depression in the empty nest elderly from the Sichuan Longmenshan fault earthquake. Geriatr Gerontol Int 2017; 17: 2143-2149

23. Qi F. The level and influencing factors of anxiety, depression and subjective well-being among emptynest elderly inpatients. Journal of Nursing Administration 2016; 16: 385-387,405

\section{Tables}

Table1 Demographic characteristics of the empty-nest and the non-empty-nest elderly populations $(\mathrm{n}=1452)$. 


\begin{tabular}{|c|c|c|c|c|}
\hline \multirow[t]{2}{*}{ Characteristics } & \multirow{2}{*}{$\begin{array}{c}\text { Empty-nest elderly } \\
{[\mathrm{n}(\%)]}\end{array}$} & \multicolumn{2}{|c|}{ Non-empty-nest elderly $\quad c^{2}$} & \multirow[t]{2}{*}{$P$-value } \\
\hline & & {$[\mathrm{n}(\%)]$} & & \\
\hline Gender & & & 3.635 & 0.057 \\
\hline Male & $419(51.6)$ & $298(46.6)$ & & \\
\hline Female & $393(48.4)$ & $342(53.4)$ & & \\
\hline Education level & & & 8.826 & 0.032 \\
\hline Primary school & $456(56.2)$ & $370(57.8)$ & & \\
\hline Junior high school & $191(23.5)$ & $126(19.7)$ & & \\
\hline Senior high school & $105(13.1)$ & $110(17.2)$ & & \\
\hline Bachelor or above & $59(7.3)$ & $34(5.3)$ & & \\
\hline Marital status & & & 15.757 & 0.000 \\
\hline Married & $594(73.2)$ & $406(63.4)$ & & \\
\hline Single & $218(26.8)$ & $234(36.6)$ & & \\
\hline Chronic disease & & & 16.495 & 0.001 \\
\hline No & $170(20.9)$ & $128(20.0)$ & & \\
\hline Yes,1 type & $351(43.2)$ & $296(46.3)$ & & \\
\hline Yes,2 types & $198(24.4)$ & $180(28.1)$ & & \\
\hline Yes, more than3 types & $93(11.5)$ & $36(5.6)$ & & \\
\hline Religious belief & & & 7.428 & 0.006 \\
\hline Religious & $132(16.3)$ & $72(11.3)$ & & \\
\hline Non-religious & $680(83.7)$ & $568(88.7)$ & & \\
\hline Physical exercise & & & 6.201 & 0.045 \\
\hline Never or occasionally & $181(22.3)$ & $146(22.8)$ & & \\
\hline Sometimes & $297(36.6)$ & 196(30.6) & & \\
\hline Often & $334(41.1)$ & 298(46.6) & & \\
\hline
\end{tabular}

Table 2 Correlation between SWB, depression and socio-demographic variables in all participants 


\begin{tabular}{lccccc}
\hline Variable & \multicolumn{5}{c}{ SWB scores } \\
& Empty & \multicolumn{4}{c}{ Non-empty } \\
& nest group & \multicolumn{2}{c}{ nest group } \\
& $r$ & $P$ & $r$ & $P$ \\
\hline GDS scores & -0.653 & $<0.01$ & -0.776 & $<0.01$ \\
Age & 0.086 & $<0.05$ & 0.065 & $>0.05$ \\
Education level & -0.125 & $<0.01$ & 0.025 & $>0.05$ \\
Economy situation & -0.108 & $<0.01$ & -0.172 & $<0.01$ \\
Monthly individual income & 0.067 & $>0.05$ & 0.109 & $<0.01$ \\
\hline
\end{tabular}

Table3 Multivariate regression analysis examining variables associated with SWB in the empty nest older adults and non-empty nest participants ${ }^{\dagger}$

\begin{tabular}{lccccccccccc}
\hline \multicolumn{1}{c}{ Variable } & \multicolumn{1}{c}{ Empty nest group } & & \multicolumn{7}{c}{ Non-empty nest group } \\
& \multicolumn{1}{c}{$B$} & $\mathrm{SE}$ & $\mathrm{b}$ & $t$ & $P$ & $B$ & $\mathrm{SE}$ & $\mathrm{b}$ & $t$ & $P$ \\
\hline Age & 0.025 & 0.012 & 0.129 & 1.996 & 0.046 & 0.006 & 0.013 & 0.029 & 0.442 & 0.659 \\
Education level & -0.139 & 0.054 & -0.093 & -2.566 & 0.015 & 0.140 & 0.059 & 0.086 & 2.371 & 0.018 \\
Marital status & -0.150 & 0.062 & -0.081 & -2.427 & 0.015 & -0.170 & 0.161 & -0.059 & -1.059 & 0.290 \\
Living mode & 0.217 & 0.054 & 0.114 & 4.038 & 0.000 & -0.117 & 0.119 & -0.038 & -0.985 & 0.325 \\
Religious belief & -0.271 & 0.104 & -0.070 & -2.593 & 0.010 & -0.078 & 0.123 & -0.016 & -0.636 & 0.525 \\
GDS scores & -0.052 & 0.002 & -0.655 & -23.749 & 0.000 & -0.063 & 0.002 & -0.784 & -28.271 & 0.000 \\
\hline
\end{tabular}

${ }^{\dagger}$ Adjusted model for age, gender, education level, marital status, child visit intervals, economy situation, monthly individual income, living mode, religious belief, physical exercise, chronic disease, and Geriatric Depression Scale (GDS) scores. ${ }^{\ddagger} R^{2}=0.470$, adjusted $R^{2}=0.469 .{ }^{\S} R^{2}=0.622$, adjusted $R^{2}=0.611$.

Table4 Multivariate regression analysis examining variables associated with depression in the empty nest older adults and non-empty nest participants ${ }^{\dagger}$ 


\begin{tabular}{|c|c|c|c|c|c|c|c|c|c|c|}
\hline \multirow[t]{2}{*}{ Variable } & \multicolumn{5}{|c|}{ Empty nest group ${ }^{\ddagger}$} & \multicolumn{5}{|c|}{ Non-empty nest group ${ }^{\S}$} \\
\hline & $B$ & $\mathrm{SE}$ & $\mathrm{b}$ & $t$ & $P$ & $B$ & $\mathrm{SE}$ & $\mathrm{b}$ & $t$ & $P$ \\
\hline Economy situation & 0.928 & 0.653 & 0.046 & 1.421 & 0.156 & 1.957 & 0.624 & 0.095 & 3.135 & 0.002 \\
\hline Monthly individual & -0.004 & 0.001 & -0.189 & -5.753 & 0.000 & -0.005 & 0.001 & -0.235 & -7.597 & 0.000 \\
\hline \multicolumn{11}{|l|}{ income } \\
\hline Living mode & -1.612 & 0.675 & -0.067 & -2.389 & 0.017 & -0.719 & 1.328 & -0.019 & -0.548 & 0.588 \\
\hline Religious belief & -0.271 & 0.104 & -0.070 & -2.593 & 0.010 & -2.811 & 1.465 & -0.047 & -1.919 & 0.055 \\
\hline Physical exercise & -2.107 & 0.614 & -0.091 & -3.434 & 0.001 & -0.300 & 0.637 & -0.013 & -0.471 & 0.638 \\
\hline SWB scores & -8.135 & 0.337 & -0.643 & -24.148 & 0.000 & -9.089 & 0.311 & -0.736 & -29.234 & 0.000 \\
\hline
\end{tabular}

$\dagger^{\dagger}$ Adjusted model for age, gender, education level, marital status, child visit intervals, economy situation, monthly individual income, living mode, religious belief, physical exercise, chronic disease, and SWB scores. ${ }^{\ddagger} R^{2}=0.480$, adjusted $R^{2}=0.469 .{ }^{\S} R^{2}=0.646$, adjusted $R^{2}=0.637$. 